\title{
Nerve fibre size in the carpal tunnel syndrome
}

\author{
P. K. THOMAS ${ }^{1}$ AND P. M. FULLERTON ${ }^{1}$ \\ From the Department of Neurology, the Middlesex Hospital, and Department \\ of Anatomy, University College, London
}

The syndrome due to compression of the median nerve in the carpal tunnel was first defined by Ramsey Hunt $(1911,1914)$ and Marie and Foix (1913), although its relationship to the acroparaesthesia syndrome was not appreciated until recently (see Kremer, Gilliatt, Golding, and Wilson, 1953). Marie and Foix (1913) examined the pathological changes in a single case, but no further studies on the histological alterations in this condition have appeared since. Recently, the opportunity presented itself for such an examination in a patient who died from an unrelated disorder. Particular attention has been given to alterations in nerve fibre size, which are of interest in relation to the changes that occur in nerve conduction (Simpson, 1956; Carpendale, 1956; Thomas, 1960).

\section{CASE REPORT}

Mrs. E.P., aged 64, attended the Out-patient Department of the Middlesex Hospital in January 1961 complaining of attacks of 'pins and needles' in the fingers of the right hand for six years. The attacks were most severe at night and she was often awakened by them. Three months before attending hospital she began to be aware of difficulty in performing fine movements with the right hand and of weakness of the grip, noticing that thumb movements were particularly affected. For about six weeks she had suffered from similar but milder tingling in the fingers of the left hand.

On examination, abnormalities were limited to the hands. There was gross wasting and weakness of the right abductor pollicis brevis and very slight wasting and weakness of this muscle on the left. Sensory testing revealed slight blunting to pin prick over the tips of the thumb, index, and middle fingers of the right hand, sensation on the left being normal. Neurological examination was otherwise normal.

On the basis of the history and examination, a clinical diagnosis of the carpal tunnel syndrome, severe on the right and mild on the left, was made.

In March 1961, while awaiting admission for surgical treatment, the patient had a right-sided focal epileptic attack. Following this attack she became mildly dysphasic. She was admitted to hospital under the care of Dr. M. Kremer on 8 April 1961 and was found to have a 'Present address: The National Hospital, Queen Square, London. left fronto-parietal astrocytoma (grade IV). She developed a progressive right hemiparesis and died on 6 June.

It is possible that the weakness in the right hand was partially due to the cerebral tumour. However, the long history of nocturnal paraesthesiae and the finding of gross partial thenar atrophy with sensory changes limited to the fingers supplied by the median nerve are features so characteristic of the carpal tunnel syndrome that there can be no doubt as to the existence of median nerve compression at the wrist.

\section{ELECTROPHYSIOLOGICAL STUDIES}

Motor nerve conduction was measured as describe $\frac{\Phi}{6}$ by Thomas (1960). The median nerve was stimulate by a probe cathode, $1 \mathrm{~cm}$. in diameter, at two sites namely about $2 \mathrm{~cm}$. above the distal wrist creaseg and just below the elbow crease. The anode was metal plate placed over the outer aspect of the uppege arm. Rectangular stimulus pulses of $100 \mu$ sec. $^{-}$ duration were delivered through an isolating transformer, the stimulus strength being adjusted so that it was supramaximal for motor nerve fibres. The muscle action potential was recorded through a coaxial needle electrode inserted into the abductor pollicis brevis. The action potentials were amplified and displayed on one beam of a double-beam oscilloscope, the second beam of which carried a time scale.

In a normal subject, when the median nerve is stimulated at the wrist, the average latency to the onset of the action potential recorded from the abductor pollicis brevis is $3.8 \mathrm{~m}$./sec., with a range of 2.9 to $5 \mathrm{~m}$./sec. (Thomas, 1960). The normal conduction velocity in the fastest motor nerve fibres to this muscle between the elbow and wrist is $57.2 \mathrm{~m}$. $/ \mathrm{sec}$. with a range of 51.8 to $67.1 \mathrm{~m} . / \mathrm{sec}$. (Thomas, Sears, and Gilliatt, 1959).

When the right median nerve of the patient described here was studied, the shortest latency from the wrist was found to be $9 \mathrm{~m}$./sec. (Fig. 1). Conduction velocity between the elbow and wrist for these fibres was $31.3 \mathrm{~m} . / \mathrm{sec}$. There was thus marked 


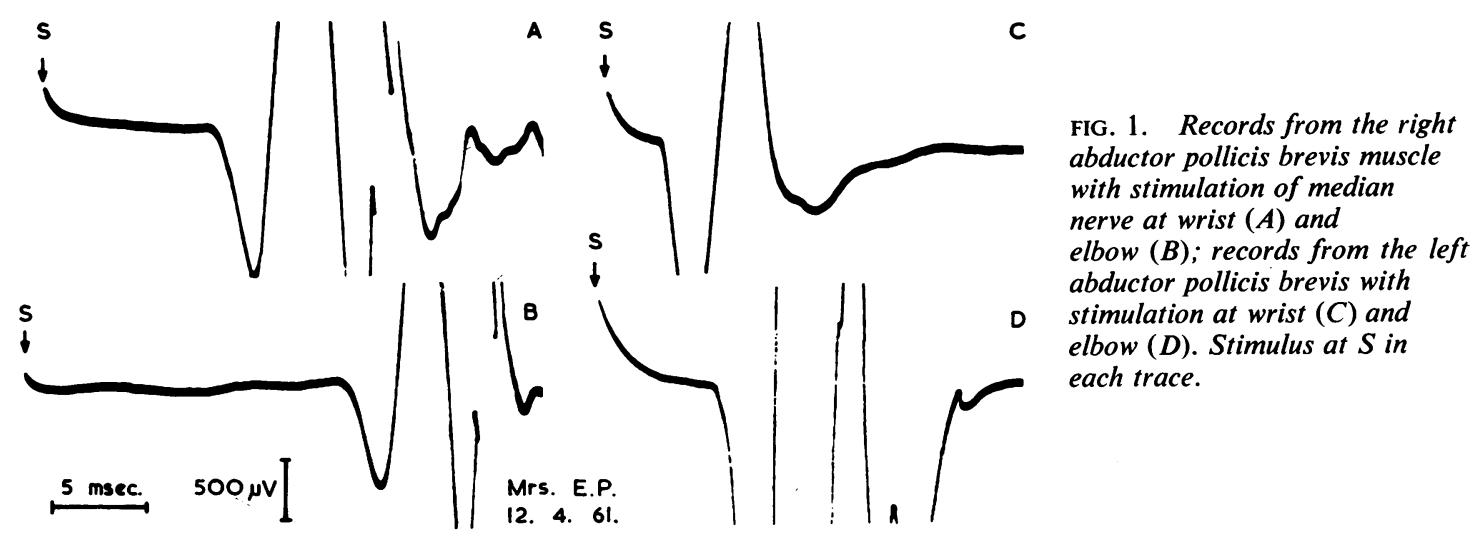

slowing of conduction distal to the wrist; conduction velocity was also below the lower limit of the normal range in the forearm, as is commonly found in patients with the carpal tunnel syndrome with considerable slowing below the wrist (Thomas, 1960).

The values for the motor nerve fibres to the left abductor pollicis brevis were within the normal range, the latency from the wrist being $3.5 \mathrm{~m}$. $/ \mathrm{sec}$. and conduction velocity over the forearm $66.6 \mathrm{~m}$./sec.

\section{NECROPSY FINDINGS}

A necropsy was performed within three hours of death. Both median nerves were dissected distally from the level of the upper arm. On the right, the nerve appeared normal as far as the lower part of the forearm, but was considerably enlarged for about $1 \mathrm{~cm}$. above the upper margin of the flexor retinaculum, being about twice the size of the nerve higher in the forearm. There was a slighter degree of enlargement extending about another $4 \mathrm{~cm}$. proximally. When the flexor retinaculum was divided, an abrupt constriction of the nerve could be seen at the level of the upper border of the retinaculum and extending through the carpal tunnel. Distal to the retinaculum, the nerve regained a more normal size. The digital nerves appeared normal. Unfortunately the branch to the thenar muscles was not identified, possibly because of atrophy resulting from severe damage.

No abnormality of the left median nerve was apparent proximal to, beneath, or distal to the flexor retinaculum.

Specimens were taken from the following sites on both sides: median nerve trunk at mid-forearm level, $1 \mathrm{~cm}$. above the flexor retinaculum and under the retinaculum; second palmar digital nerve (to medial border of thumb), third palmar digital nerve (to lateral border of index finger), and fourth palmar digital nerve (to adjacent borders of index and middle fingers); a specimen was also taken from the branch to the left thenar muscles.

\section{HISTOLOGICAL OBSERVATIONS}

The specimens were fixed in Flemming's solution at $4^{\circ} \mathrm{C}$. for four days after slitting the epineurium

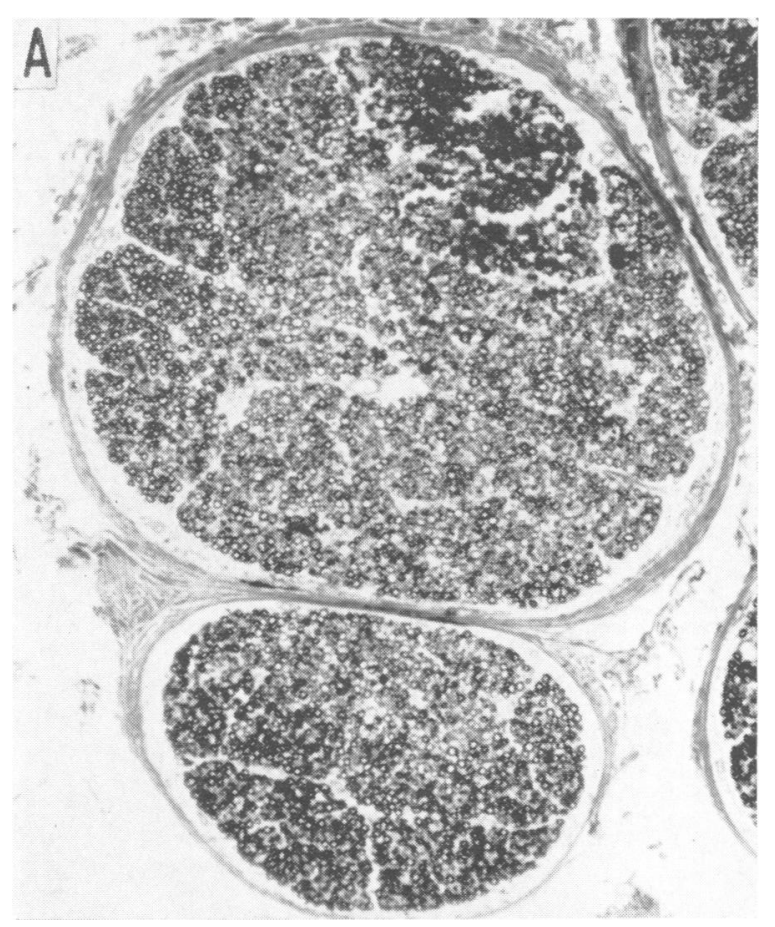

FIG. 2. A Transverse section of fascicles from right median nerve at mid-forearm level stained with Weigert's haematoxylin and light green. $\times 65$. 


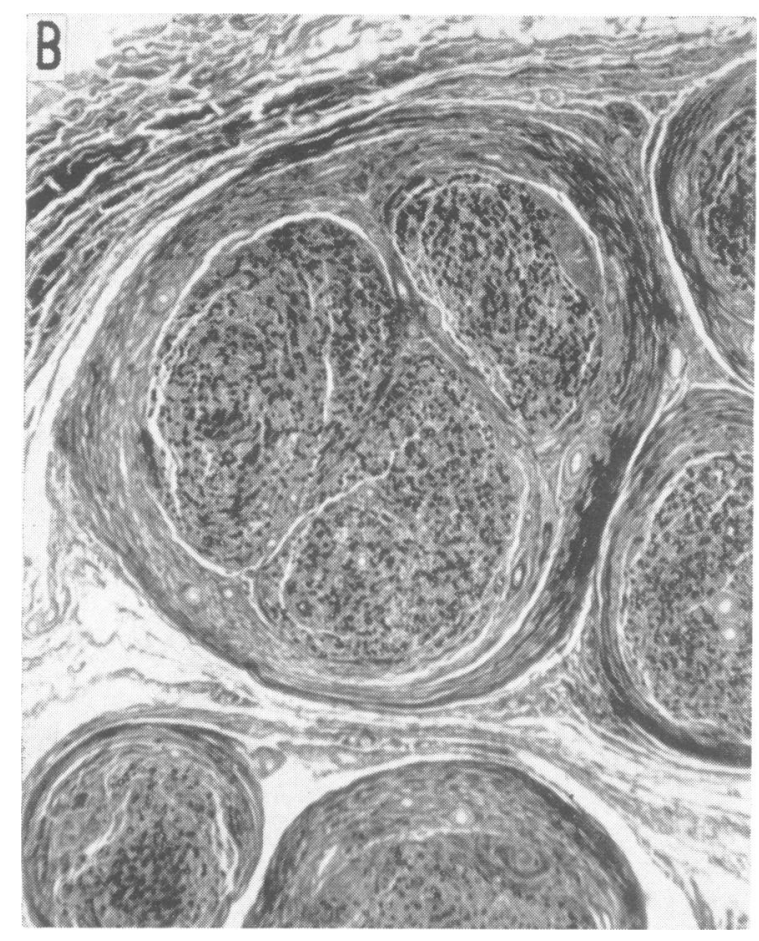

FIG. 2. B Transverse section of fascicles from right median nerve at level of flexor retinaculum stained with Weigert's haematoxylin and light green. $\times 65$.

and separating the individual fascicles to facilitate penetration of the fixative. Following embedding in paraffin wax, transverse sections $5 \mu$ thick were stained by the modified Weigert method described by Gutmann and Sanders (1943). Some sections were counterstained with light green. The quality of the sections approached that obtained from biopsy material.

The connective tissue of the nerve was not examined systematically, but a considerable increase in the thickness of the perineurium and the amount of endoneurial connective tissue was apparent in the sections taken from under the retinaculum (Fig. 2B) and at $1 \mathrm{~cm}$. above the retinaculum on both sides, these changes being greater on the right. No comment can be made on the epineurium, as this was cut to aid in the penetration of the fixative. The sections taken at mid-forearm level on both sides (Fig. 2A) showed no obvious alteration in the connective tissue. Those from the digital nerve showed an increase in the endoneurial connective tissue on the right as compared with the left.

Measurements of fibre size (external diameter of myelin sheath) were made from photographs. Because the nerves contained too many fibres for total counts to be possible, a sampling techniques was employed. All fibres lying on a $0.4 \mathrm{~mm}$. wide strip across the longest diameter of the section were photographed at a magnification of $\times 300$. Photo graphic enlargements were made to a total magnifio 3 cation of $\times 750$. Fibres were then sorted into $2 \mu$ 등.

TABLE I

NERVE FIBRE SIZE DISTRIBUTION

Site Nerve Fibre Size $(\mu)$

\begin{tabular}{lllllllllll}
\hline $2-4$ & -6 & -8 & -10 & -12 & -14 & -16 & -18 & -20 & -22 & Total
\end{tabular}

Mid-forearm

Left

Right

546

440

$1 \mathrm{~cm}$. above retinaculum

Left

Right

Under retinaculum

Left

Right

Second palmar digital

Left

Right

Third palmar digital

Left

Right

Fourth palmar digital

Left

Right

Branch to thenar muscles Left

362

468

1,063

999

$732 \quad 294$

$\begin{array}{ll}732 & 294\end{array}$

304

325

$604 \quad 491$

679

555

1,072
794

660

406
452

452

511
206

206

404

404
485

355

355
262

209
261

56
47

$\begin{array}{ll}56 & 18 \\ 47 & 15\end{array}$

416

60

208

19

31
4

31
4

5

2,443

$\begin{array}{lll}436 & 88 & 7\end{array}$

3,326

1,939
692
777

761

1,564

1,099

1,757

694 

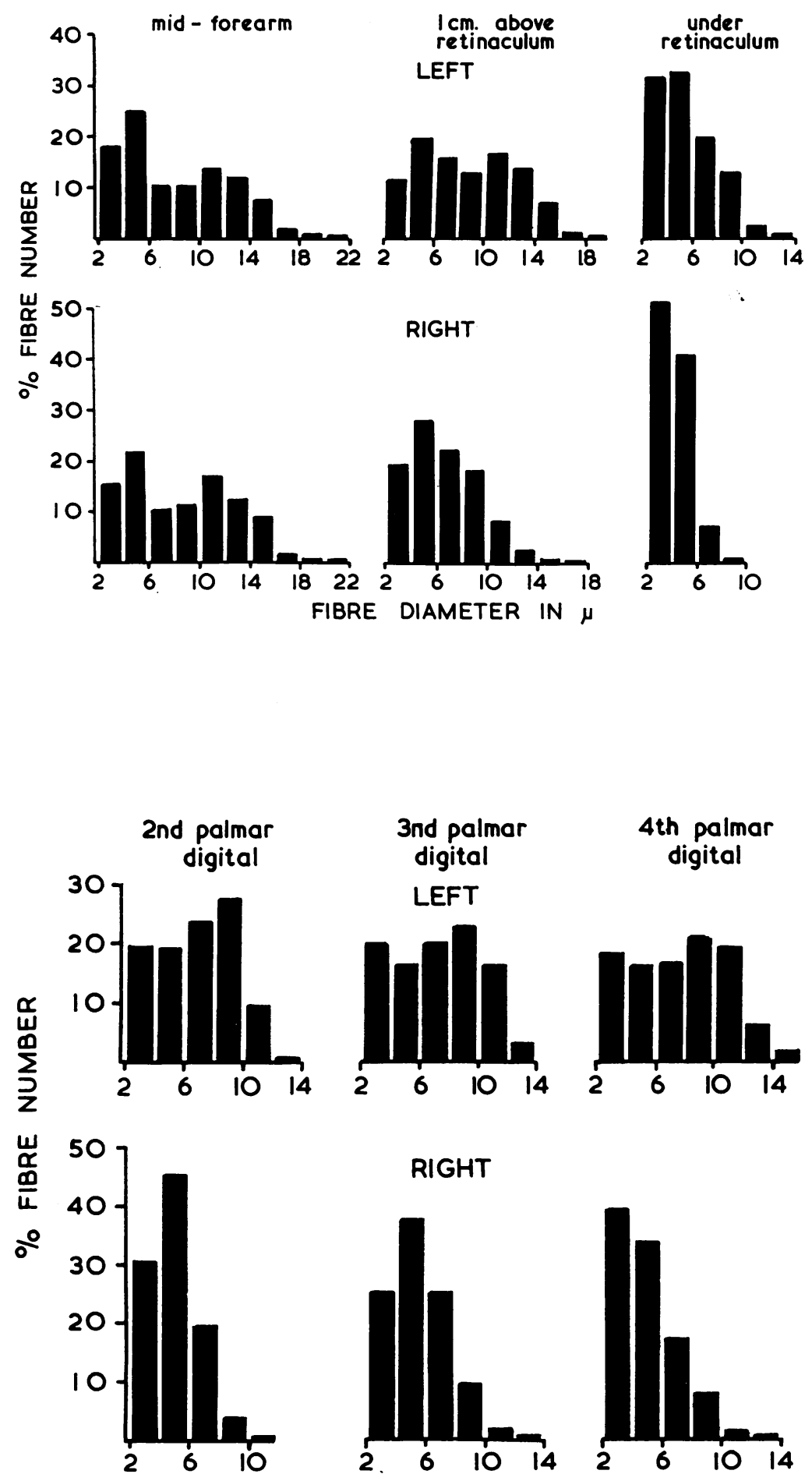

FIG. 4. Histograms of percentage frequency distribution for $2 \mu$ fibre diameter groups in second, third, and fourth palmar digital nerves of left and right hands.

FIG. 3. Histograms of percentage frequency distribution for $2 \mu$ fibre diameter groups in left and right median nerves at mid-forearm level, $1 \mathrm{~cm}$. above the flexor retinaculum and under the retinaculum. 
A50 $08008 \%$

$380.00 \%$

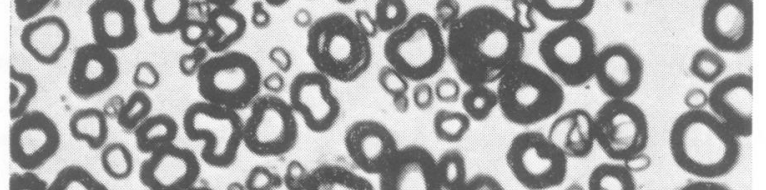

- $409000^{\circ}$

\%

80030800

.

50.8 $800 \%$

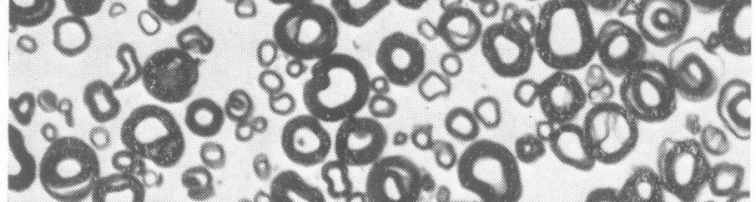

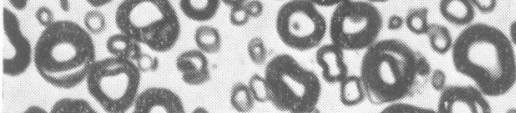
ne $9000 \%$

$B_{3}$

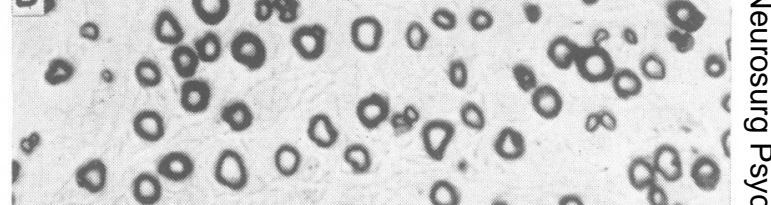

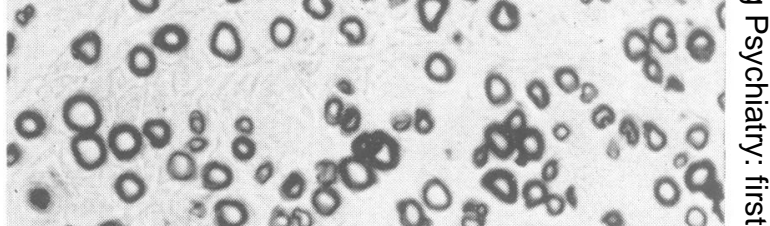

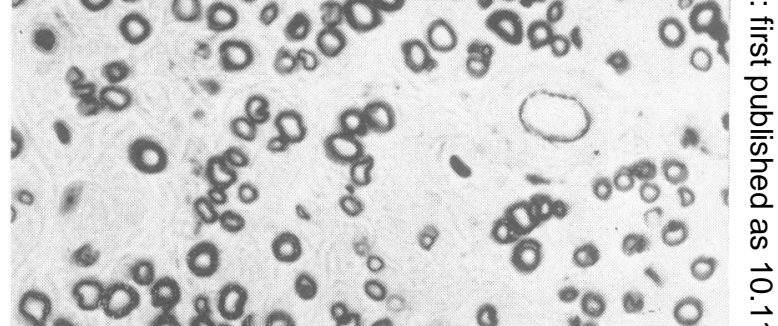

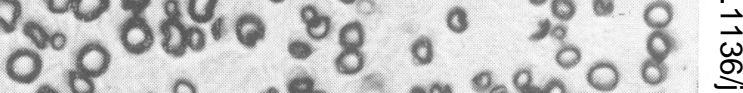
$.080^{\circ} 00.00 \%$

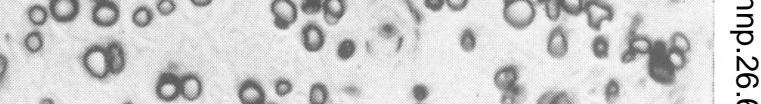

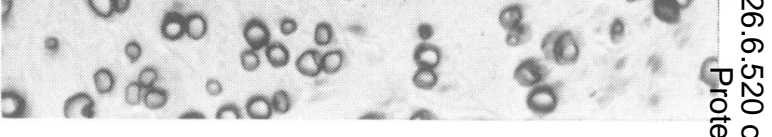

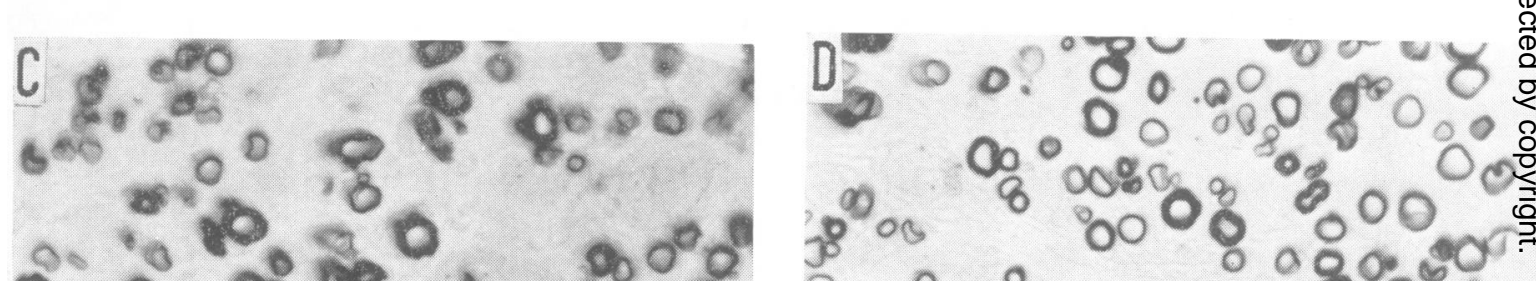

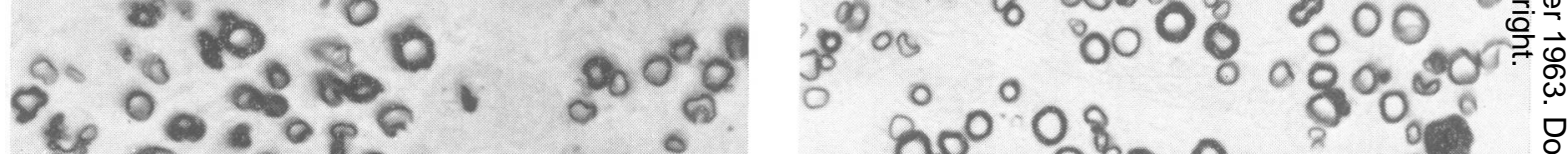

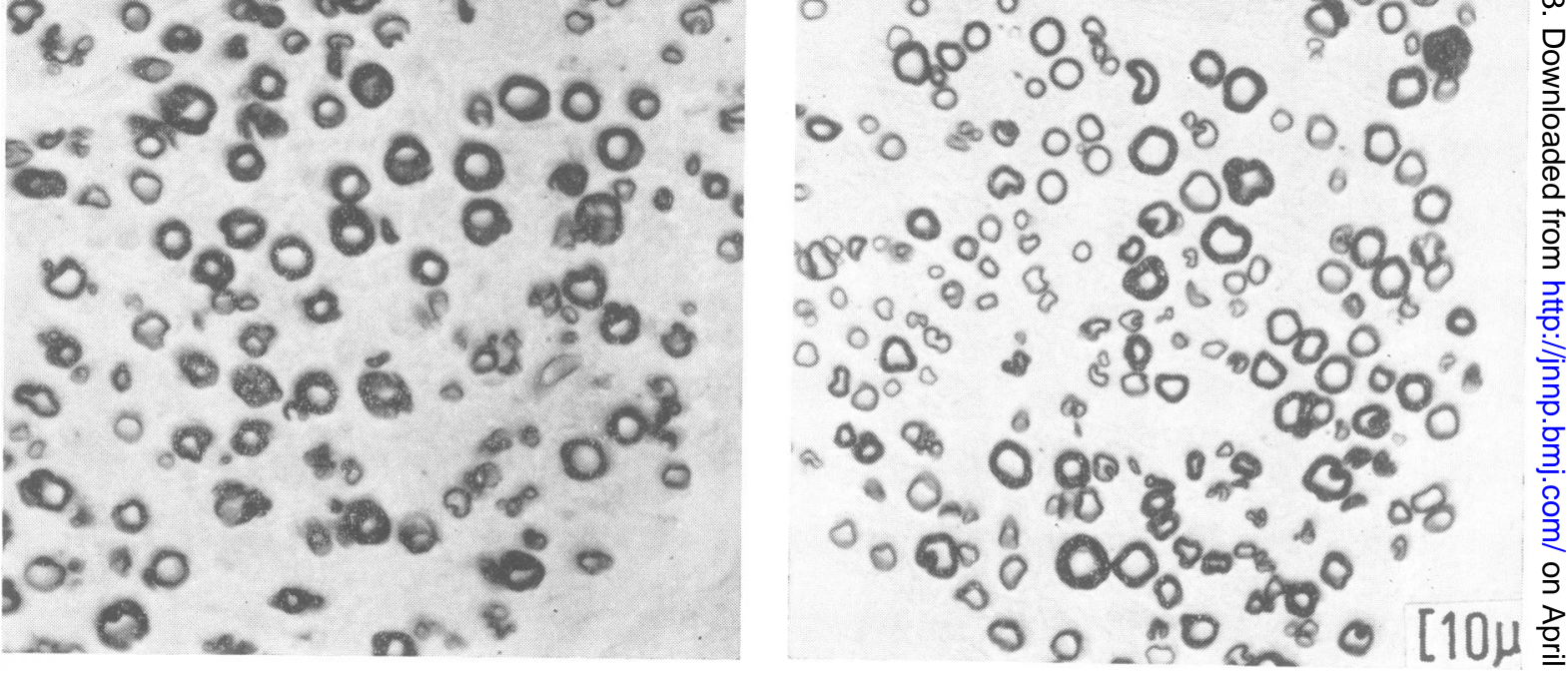

FIG. 5. A Portion of transverse section of right median nerve at mid-forearm level. Weigert's haematoxylin $\times 480$.

B Portion of transverse section of right median nerve at level of flexor retinaculum. Weigert's haematoxylin $\times 480$.

C Portion of transverse section of right second palmar digital nerve. Weigert's haematoxylin $\times 480$.

D Portion of transverse section of right fourth palmar digital nerve. Weigert's haematoxylin $\times 480$. 
diameter groups by matching with circles scored on a Perspex square; the fibres were marked as they were counted by pricking with a needle that activated a counting device. Further details of the counting technique, together with an assessment of the errors involved, have been given by Evans and Vizoso (1951) and Fernand and Young (1951). The counts of nerve fibre size are shown in Table I and have been presented in the form of percentage frequency histograms in Figures 3 and 4.

Sections taken at the mid-forearm level revealed similar appearances on both sides, fibre size distribution being bimodal with peaks at 4 to $6 \mu$ and 10 to $12 \mu$ with a maximum diameter of $22 \mu$. One centimetre above the flexor retinaculum, the distribution on the left was again bimodal, with the same modal values, and with a maximum diameter of $20 \mu$. On the right, however, there was a relative loss of the larger fibres so that the distribution had become unimodal, although the maximum diameter was $18 \mu$. Under the retinaculum, sections from both sides showed a sharp diminution in fibre size, particularly on the right, where no fibres larger than $10 \mu$ were present, the majority being between 2 and $6 \mu$. The distributions were unimodal on both sides.

In the digital nerves, all sections were unimodal on the right. On the left, although the distributions were not clearly bimodal, there were suggestions of peaks at 2 to $4 \mu$ and 8 to $10 \mu$. Fibre size was greater on the left with maximum values of 14 to $16 \mu$ as compared with 12 to $14 \mu$ on the right, where there was a relative preponderence of fibres in the 2 to $8 \mu$ groups.

A statistical comparison ( $t$ test) was made between mean fibre diameter on the two sides at the different levels, the individual values being given in Table II. There was no significant difference at the midforearm level, whereas at all other sites the differences were highly significant $(P<0 \cdot 001)$. Furthermore, sections from the digital nerves on both sides, and also from the branch to the thenar muscles on the left, showed a consistently larger fibre size than in those taken from under the flexor retinaculum (see Table II). The mean values for fibre diameter under the retinaculum on the two

TABLE II

MEAN FIBRE DIAMETER WITH STANDARD DEVIATION

Mean Fibre Diameter $(\mu)$

\begin{tabular}{lll} 
& Left & Right \\
\hline Mid-forearm & $8 \cdot 09 \pm 4 \cdot 16$ & $8 \cdot 14 \pm 4 \cdot 34$ \\
1 cm. above retinaculum & $8 \cdot 56 \pm 3 \cdot 75$ & $6 \cdot 61 \pm 2.77$ \\
Under retinaculum & $5 \cdot 46 \pm 2 \cdot 25$ & $4 \cdot 12 \pm 1 \cdot 27$ \\
Second palmar digital & $6 \cdot 80 \pm 2 \cdot 58$ & $4.97 \pm 1 \cdot 67$ \\
Third palmar digital & $7 \cdot 19 \pm 2.92$ & $5 \cdot 51 \pm 2.05$ \\
Fourth palmar digital & $7 \cdot 66 \pm 3 \cdot 27$ & $4.99 \pm 2.06$ \\
Muscular branch & $7 \cdot 35 \pm 3 \cdot 25$ &
\end{tabular}

sides were compared statistically ( $t$ test) with the mean values for the digital nerves: in both the right and left hands, the differences were all highly significant $(P<0.001)$.

Figure 5, A to $D$, shows representative areas from the right median nerve taken from the mid-forearm level (A), beneath the retinaculum (B), and from the second and fourth palmar digital nerves (C and D).

\section{DISCUSSION}

Little information is available concerning fibre size in the median nerve of normal subjects. Some observations were reported by Ranson, Droegemueller, Davenport, and Fisher (1935). These authors found that in the median nerve at the wrist the distribution of myelinated fibres was bimodal with peaks at 2 to $3 \mu$ and 8 to $9 \mu$. The large majority of fibres were less than $12 \mu$ in diameter, but there were a few with diameters of up to $15 \mu$. A similar distribution was found in the palmar digital nerves. Despite the relative lack of normal data, certain useful conclusions can be derived from the present results by comparing the more severely affected right side with the less affected left side. On the right, the patient had severe symptoms and showed gross muscle weakness and wasting together with sensory impairment of median distribution in the hand. On the left, there were relatively trivial symptoms, only slight muscle wasting and no sensory loss.

At the mid-forearm level, there was no significant difference in fibre diameter between the two sides. One centimetre above the flexor retinaculum the right side showed a reduction in fibre diameter and both sides displayed an increase in the amount of connective tissue present in the nerve. This finding can be correlated with the observation that the threshold for electrical stimulation of the median nerve may be moderately elevated for several centimetres above the wrist in cases of the carpal tunnel syndrome. Weiss (1944) and Weiss and Hiscoe (1948) have reported an increase in fibre size proximal to experimental nerve constriction in animals and have sought to explain this in terms of the damming of a normal proximo-distal flow of axoplasm. There is now a considerable body of evidence for the existence of such a flow (see Droz and Leblond, 1962; Miani, 1962). However, an increase in fibre size was certainly not evident $1 \mathrm{~cm}$. above the retinaculum, although the region immediately above the compressed zone was not examined. On the other hand, Duncan (1948) found that, in general, there was a reduction in axon diameter and myelin thickness proximal to experimental constrictions. It may be that differences in experimental technique account for this disparity and further studies on the effects of nerve compres- 
sion on fibre size appear necessary. Moreover, it is not clear how closely the results of experimental constrictions in animals can be compared with the effects of compression of the median nerve in the carpal tunnel in man, where a much greater length of nerve is involved.

Sections taken from the compressed region of nerve at the level of the flexor retinaculum on both sides showed a sharp reduction in fibre size. This is also evident by comparison with the results of Ranson et al. (1935). With regard to the effect of nerve compression on fibre size, in acute experiments Causey (1948) showed that axoplasm becomes displaced from the compressed segment into the adjacent parts of the nerve. In chronic experiments, Weiss and Hiscce (1948) and Duncan (1948) demonstrated that fibre size becomes diminished both at and distal to the site of compression, and Weiss and Hiscoe suggested that the reduction distal to the compression is the result of a throttling effect on axoplasmic flow.

In the sections taken distal to the compressed region of nerve, fibre size in the digital nerves on the more affected right side was found to be smaller than on the left. On the left, maximum fibre size was similar to that reported for the palmar digital nerves by Ranson et al. (1935), and although the distributions were not clearly bimodal, there was some indication of peaks with the same modal values as were found by these authors. As total counts were not made, it is difficult to be certain whether the reduction in fibre size in the digital nerves on the right was the result of the loss or branching of larger fibres or due to a reduction in size of compressed fibres distal to the lesion. However, the fact that mean fibre size was larger in the digital nerves than under the retinaculum strongly suggests that at least some fibres were compressed in the carpal tunnel with accompanying diminution in diameter and that they expanded in size distally. Although considered unlikely by Weiss and Hiscoe (1948), Duncan (1948) thought that compressed fibres might increase in size below an experimental constriction if followed far enough distally, and this has been confirmed by recent similar experiments (Thomas, to be published). Simpson and Young (1945) also reported some evidence to suggest that fibres might increase in size distal to a zone of constriction.

Previous investigations have made it clear that local ischaemia secondary to compression of the median nerve in the carpal tunnel is involved in the production of the intermittent symptoms of pain and paraesthesiae in the carpal tunnel syndrome (Gilliatt and Wilson, 1953; Fullerton, 1963). Wasting and persisting sensory loss are presumably due to interruption of fibres in the compressed region. How far ischaemia plays a part in the production of the structural changes in the nerve fibres is at present uncertain, but recent experimental studies by Fullerton (1963) have suggested that the structural changes are more likely to be the direct result of compression. Evidence for a reduction in fibre diameter under the flexor retinaculum produced by compression has been provided by the present results. On the other hand, Garven, Gairns, and Smith (1962) have reported considerable loss of large myelinated fibres in nerves from patients with chronic occlusive vascular disease of the leg, and it is therefore possible that loss of the larger myelinated fibres in the carpal tunnel syndrome may be partly due to repeated ischaemic episodes.

In a high proportion of patients with the carpal tunnel syndrome, measurements of nerve conduction time in the motor nerve fibres to the abductor pollicis brevis with stimulation of the median nerve just above the wrist have shown a slowing of conduction (Simpson, 1956; Carpendale, 1956; Thomas, 1960). In the present patient, slowing was present on the right but not on the left. There has been some uncertainty as to its explanation, but as the slowing may take as long as 18 months to recover after surgical decompression of the nerve (see Goodman and Gilliatt, 1961), it has been suggested (Thomas, 1960) that structural changes in the nerve must be responsible. The marked reduction in fibre size under the retinaculum on the right as compared with the left strongly supports this view, although it is unfortunate that the branch to the thenar muscles on the right was not obtained.

The present patient also showed slowing of conduction velocity in the forearm, as was found in a proportion of patients with the carpal tunnel syndrome by Thomas (1960). It is possible that the changes produced by the lesion extended far enough above the wrist to affect conduction velocity in the forearm. On the other hand, it is known that the slowing of conduction velocity may extend as high as the upper arm. The slowing might therefore be the result of selective damage to the larger fibres at the wrist, so that recordings were only made from fibres of smaller diameter with slower conduction velocities that persisted through the lesion. The question has been discussed more fully elsewhere (Thomas, 1960).

The changes in the case reported by Marie and Foix (1913) were clearly more severe than in our patient. The median nerve in their case increased in size progressively along the forearm from above downwards and showed a nodular enlargement just above the retinaculum. There was a sharp constriction in its size under the retinaculum. The 
nodular enlargement was associated with an extensive connective tissue proliferation that was both interfascicular and intrafascicular. Above the nodule, the myelinated fibres were more scattered than higher in the nerve. From the level of the nodular enlargement into the constricted zone, a progressive loss of myelin sheaths was evident, and distal to the constricted region, they had almost completely disappeared. The swelling of the nerve above the flexor retinaculum described by Marie and Foix has been noted by subsequent writers, e.g., Brain, Wright, and Wilkinson (1947). It is also seen above the site of constriction in cases of compression of the ulnar nerve in the cubital tunnel (Feindel and Stratford, 1958). This, as has already been suggested (see Brain et al., 1947), is probably comparable to the swelling of the nerve observed proximal to experimental constrictions (Weiss, 1943). Weiss considered that the swelling was due to the accumulation of endoneurial fluid that normally flows in a proximo-distal direction above the site of the compression, although his explanation received criticism from Denny-Brown and Brenner (1944). These authors considered that the swelling was due to oedema related to local vascular stasis, and the fact that it was greater proximally was because of a relative impairment of blood supply on the distal side of the lesion as Weiss had sectioned the nerves distal to the lesion. Whatever the explanation of the swelling, it is clear that in cases of compression of the median nerve in the carpal tunnel the swelling is greater on the proximal side.

\section{SUMMARY}

Measurements of the diameter of myelinated nerve fibres have been made in both median nerves in a patient with the carpal tunnel syndrome who died from an unrelated disorder. The patient had prominent symptoms in the right hand with both motor and sensory abnormalities on examination, and only mild symptoms with slight muscle wasting on the left. Conduction time in the motor nerve fibres to the abductor pollicis brevis was reduced below the wrist on the right but was normal on the left. There was also some slowing over the right forearm.

Sections were examined at the mid-forearm level, $1 \mathrm{~cm}$. above the flexor retinaculum, under the retinaculum, and in the digital nerves on both sides. Fibre size did not differ between the right and left sides at the mid-forearm level, but showed some reduction $1 \mathrm{~cm}$. above the retinaculum on the right. Under the retinaculum, there was a striking reduction in fibre size on both sides, particularly on the right. The digital nerves on the right showed a reduction in fibre diameter as compared with the left, but fibre size was greater in the digital nerves on both sides than under the retinaculum.

The significance of these changes is discussed in relation to the results of experimental nerve constrictions in animals, and in relation to the changes in nerve conduction seen in the carpal tunnel syndrome.

We are indebted to Dr. Michael Kremer for his help and encouragement and to Dr. J. T. Aitken, Professor R. W. Gilliatt, and Professor J. Z. Young for helpful discussion. We also wish to thank Mr. J. Threadgold for technical assistance, Mr. H. Artinian for the photographs, and Professor D. G. Cameron for providing generous facilities while one of us (P.K.T.) held an appointment in the Department of Medicine at the Montreal General Hospital.

\section{REFERENCES}

Brain, W. Russell, Wright, A. Dickson, and Wilkinson, M. (1947). Lancet, 1, 277.

Carpendale, M. T. F. (1956). M.S. Thesis (Phys. Med.), University of Minnesota.

Causey, G. (1948). J. Anat. (Lond.), 82, 262.

Denny-Brown, D., and Brenner, C. (1944). Arch. Neurol. Psychiat. (Chicago), 52, 1

Droz, B., and Leblond, C. P. (1962). Science, 137, 1047.

Duncan, D. (1948). J. Neuropath. exp. Neurol., 7, 261.

Evans, D. H. L., and Vizoso, A. D. (1951). J. comp. Neurol., 95, 429.

Feindel, W., and Stratford, J. (1958). Canad. J. Surg., 1, 287.

Fernand, V. S. V., and Young, J. Z. (1951). Proc. roy. Soc. B, 139, 38.

Fullerton, P. M. (1963). J. Neurol. Neurosurg. Psychiat., 26, 385.

Garven, H. S. D., Gairns, F. W., and Smith, G. (1962). Scot. med. J., 7, 250.

Gilliatt, R. W., and Wilson, T. G. (1953). Lancet, 2, 595.

Goodman, H. V., and Gilliatt, R. W. (1961). Ann. phys. Med., 6, 137.

Gutmann, E., and Sanders, F. K. (1943). J. Physiol. (Lond.), 101, 489.

Hunt, J. Ramsey. (1911). Amer. J. med. Sci., 141, 224.

- (1914). Rev. Neurol. Psychiat., 12, 137.

Kremer, M. Gilliatt, R. W., Golding, J. S. R., and Wilson, T. G. (1953). Lancet, 2, 590.

Marie, P., and Foix (1913). Rev. neurol., 26, 647.

Miani, N. (1962). Nature (Lond.), 193, 887.

Ranson, S. W., Droegemueller, W. H., Davenport, H. K., and Fisher C. (1935). Res. Publ. Ass. nerv. ment. Dis., 15, 3.

Simpson, J. A. (1956). J. Neurol. Neurosurg. Psychiat., 19, 275.

Simpson, S. A., and Young, J. Z. (1945). J. Anat. (Lond.), 79, 48.

Thomas, P. K. (1960). Neurology (Minneap.), 10, 1045.

(1963). To be published.

- Sears, T. A., and Gilliatt, R. W. (1959). J. Neurol. Neurosurg. Psychiat., 22, 175.

Weiss, P. (1943). Anat. Rec., 86, 491. (1944). Ibid., 88, 464.

$\longrightarrow$, and Hiscoe, H. B. (1948). J. exp. Zool., 107, 315. 
PARAPLEGIA The Official Journal of the International Medical Society of Paraplegia. Vol. 1, no. 1, May 1963. Edited by L. Guttman. (£1.) Edinburgh and London: E. \& S. Livingstone Ltd.

This new quarterly journal is very well produced and we wish it every success.

W. RITCHIE RUSSELL

PROCEEDINGS OF THE AUSTRALIAN ASSOCIATION OF NEUROLOGISTS Vol. 1, No. 1, May 1963. Edited by E. Graeme Robertson. (Pp. 74; illustrated). Published by the Australian Association of Neurologists.

Many will welcome this new venture under the editorship of Dr. Graeme Robertson. This first volume has been published at the expense of Ciba Limited, and as no price is mentioned presumably the way to get a copy is to write for a free issue to The Editor, 33 Collins Street, Melbourne, C.1, Victoria, Australia. If this is to grow into a more formidable journal, it will probably be necessary to widen the scope substantially beyond a report of the proceedings. However, we wish those concerned every success.

\section{SYMPOSIUM NEURORADIOLOGICUM (VII)}

The seventh Symposium Neuroradiologicum will be held in New York City at the Waldorf-Astoria Hotel from 20 to 25 September 1964.

In addition to essays on subjects of diagnostic and therapeutic neuroradiological interest, there will be a symposium on Radiation and the Nervous System. The latter will include essays on radiobiology, effects of radiation encountered in outer space, and the use of ultra-sound and radioisotopes in diagnosis and therapy.

The official languages of the Symposium will be English, French, German, and Spanish. Application forms may be obtained from the President, Dr. Juan M. Taveras, Neurological Institute, 710 West 168th Street, New York 32, New York.

The New York World's Fair will be in progress at the time of the Symposium.

\section{CORRECTIONS}

There are certain printing errors in the paragraphs from the paper 'Nerve fibre size in the carpal tunnel syndrome' by P. L. Thomas and P. M. Fullerton (J. Neurol Neurosurg. Psychiat., 26, 520) in the section 'Electrophysiological Studies'. The corrected paragraphs are as follows:-

In a normal subject, when the median nerve is stimulated at the wrist, the average latency to the onset of the action potential recorded from the abductor pollicis brevis is $3.8 \mathrm{msec}$, with a range of 2.9 to 5 msec. (Thomas, 1960). The normal conduction velocity in the fastest motor nerve fibres to this muscle between the elbow and wrist is $57.2 \mathrm{~m}$. $/ \mathrm{sec}$. with a range of 51.8 to $67.1 \mathrm{~m} . / \mathrm{sec}$. (Thomas, Sears, and Gilliatt, 1959).

When the right median nerve of the patient described here was studied, the shortest latency from the wrist was found to be 9 msec. (Fig. 1). Conduction velocity between the elbow and wrist for these fibres was $31.3 \mathrm{~m}$./sec. There was thus marked slowing of conduction distal to the wrist; conduction velocity was also below the lower limit of the normal range in the forearm, as is commonly found in patients with the carpal tunnel syndrome with considerable slowing below the wrist (Thomas, 1960).

The values for the motor nerve fibres to the left abductor pollicis brevis were within the normal range, the latency from the wrist being $3.5 \mathrm{msec}$. and conduction velocity over the forearm $66.6 \mathrm{~m}$. $/ \mathrm{sec}$.

The authors of 'Studies in spina bifida' Part IV ( $J$. Neurol. Neurosurg. Psychiat., 26, 545) wish to make an amendment to the sixth line of the first paragraph of the Discussion. It should read 'Two cases out of 15 operated upon during the first week of life...'

\section{NOTICE TO CONTRIBUTORS}

Would intending authors kindly note that in future they are requested to put in their lists of references the full title of the paper quoted together with the numbers of the first and last pages. An example of how references should now be set out can be seen on the inside front cover under the general instructions to contributors. 